\section{JURNAL ABDIMAS

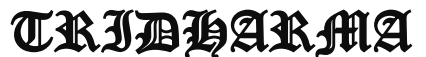

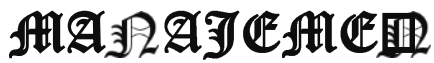

P-ISSN 0000-0000, E-ISSN 0000-0000

Jurnal ABDIMAS Vol. 1,No.1, Agustus 2019, Hal (102-110)

@ Prodi Manajemen Fakultas Ekonomi Universitas Pamulang

Email: abdimasjurnal.unpam@gmail.com Telp: (021) 741-2566

\title{
MEMBANGUN JIWA KEPEMIMPINAN ENTERPRENEUR MUDA DALAM \\ MENGHADAPI ERA GLOBALISASI UNTUK KARYAWAN \\ PT. TEKNOLABINDO PENTA PERKASA
}

\begin{abstract}
Vega Anismadiyah, Sulaiman, Aidil Amin Effendy, Bambang Purnomo, Hendri Prasetyo
Dosen Fakultas Ekonomi Universitas Pamulang
\end{abstract}

\section{Email dosen02218@unpam.ac.id, dosen01902@ unpam.ac.id , dosen00967@unpam.ac.id ,dosen02142@unpam.ac.id , dosen00806@unpam.ac.id}

\begin{abstract}
ABSTRAK
Pengabdian Kepada Masyarakat ini berjudul Membangun Jiwa Kepemimpinan Enterpreneur Muda Dalam Menghadapi Era Globalisasi Untuk Karyawan PT. Teknolabindo Penta Perkasa Jakarta.

Tujuan pengabdian kepada masyarakat ini adalah untuk membangun jiwa kepemimpinan dan jiwa enterpreneur bagi generasi muda di era globalisasi. Pengabdian kepada masyarakat ini dilakukan dalam beberapa kegiatan. Pertama survey lapangan, mencari tahu hal apa yang dibutuhan oleh karyawan PT. Teknolabindo Penta Perkasa. Kedua sosialisasi, yaitu bersilaturahim dengan manajemen PT. Teknolabindo Penta Perkasa dan menyampaikan tujuan diadakannya kegiatan ini. Ketiga Pelaksanaan, tahapan ini dijalankan sesuai dengan perencanaan yang telah disepakati di awal kegiatan.

Tim pelaksana kegiatan pengabdian kepada masyarakat ini adalah dosen-dosen Universitas Pamulang Fakultas Ekonomi Program Studi Manajemen sebanyak lima orang.

Tim ini memberikan materi kepada kaum milenial yang bekerja di PT. Teknolabindo Penta Perkasa tentang pentingnya jiwa kepemimpinan dan jiwa enterpreneur dalam kehidupan kemasyarakatan.

Kesimpulan dari kegiatan pengabdian masyarakat ini adalah kaum milenial kurang memiliki jiwa kepemimpinan yang baik sehingga cenderung bersikap individualis dan apatis terhadap orang lain dan lingkungan sekitar. Kaum milenial juga belum mengembangkan jiwa enterpreneur sehingga karakter-karakter baik yang menyertai jiwa enterpreneur seperti disiplin, jujur, pantang menyerah dan kreatif belum terimplementasi dengan baik dalam diri
\end{abstract}



JURNAL ABDIMAS
P-ISSN 0000-0000, E-ISSN 0000-0000

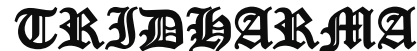
Jurnal ABDIMAS Vol. 1,No.1, Agustus 2019, Hal (102-110)
@ Prodi Manajemen Fakultas Ekonomi Universitas Pamulang
AlA
Email: abdimasjurnal.unpam@gmail.com Telp: (021) 741-2566

mereka. Dengan adanya pengabdian ini, generasi muda diharapkan dapat menumbuhkan jiwa kepemimpinan dalam diri mereka dan juga mengembangkan jiwa enterpreneur agar menjadi pribadi yang berjiwa pemimpin dan profesional sehingga bisa berperan optimal baik di tempat kerja maupun di lingkungan tempat tinggalnya.

\section{Kata kunci : jiwa kepemimpinan, jiwa enterpreneur, kaum muda}

\section{ABSTRACT}

The tittle of this Service To the community is Building Up the leadership and enterpreneurship to the millenial in the globalization era at PT. Teknolabindo Penta Perkasa.

The aim of this service is building up leadership and entepreneurship to the young generation in globalization era. This service takes some activities. The first thing is find out what is needed by the workers. Then socializing with the management team about the aim of this activity. Then implemantation turn out as planned.

This team gives some materials to the young millenials who work in PT Teknolabindo Penta Perkasa about the importance of leadership and enterpreneurship in society.

The conclusion of this service is the young millenial less of leadership so that they tend to have individual and apathetic personality. They also haven't developed enterpreneurship as of the good characters not inherent in them yet. With this activity, the yonger generation is expected to grow their leadership and developed their enterpreneurship as well.

Keywords : social sense, enterpreneur sense, young millenial

\section{PENDAHULUAN}

Manusia adalah makhluk hidup dengan pemikiran yang kompleks, dan segala sesuatu yang berkaitan dengan manusia menjadi tidak berbatas termasuk kemungkinan yang terjadi menjadikan manusia dan kehidupannya dinamis.

Ada banyak aspek yang berkaitan dengan manusia, diantaranya adalah hati, jiwa, dan kemanusiaan. 

JURNAL ABDIMAS
P-ISSN 0000-0000, E-ISSN 0000-0000

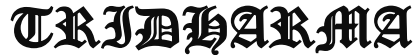
Jurnal ABDIMAS Vol. 1,No.1, Agustus 2019, Hal (102-110)
@ Prodi Manajemen Fakultas Ekonomi Universitas Pamulang
ftA
Email: abdimasjurnal.unpam@ gmail.com Telp: (021) 741-2566

Menurut KBBI, hati didefinisikan sesuatu yang ada di dalam tubuh manusia yang dianggap sebagai tempat segala perasaan batin dan tempat menyimpan pengertian (perasaan dan sebagainya).

Sedangkan jiwa menurut KBBI didefinisikan seluruh kehidupan batin manusia (yang terjadi dari perasaan, pikiran, angan-angan, dan sebagainya) dan juga sesuatu atau orang yang utama dan menjadi sumber tenaga dan semangat.

Dan kemanusiaan yang menurut KBBI didefinisikan secara manusia; sebagai manusia.

Tiga hal tersebut harus direfleksikan bagi setiap manusia jaman sekarang, karena berbagai masalah yang sedang ataupun sudah terjadi. Masalah tersebut adalah masalah yang terjadi di bidang sosial.

Berada di era globalisasi, cukup jarang menemukan orang yang berjiwa sosial tinggi. Secara garis besar jiwa kepemimpinan ini timbul akibat dari rasa tanggungjawab atas sesuatu yang dirasa harus diurus guna untuk memberikan kenyamanan bagi orang lain yang tengah kita pimpin dalam wadah kelompok untuk mencapai kemakmuran bersama dan jiwa kepemimpinan ada untuk memberikan motivasi kepada orang lain yang tengah kita pimpin. Jiwa Kepemimpinan adalah sikap yang menggambarkan kepedulian untuk melakukan sesuatu kepentingan kemanusiaan dan sosial kemasyarakatan.

Saatnya melakukan refleksi: sudahkah kita peduli pada hal di luar diri sendiri? Makin mudah kita temukan orangorang dengan sifat individualistis, bahkan mungkin kita termasuk salah satunya. Padahal, jiwa kepemimpinan adalah salah satu pelajaran dasar universal. Kepedulian menjadi sangat penting dalam hidup karena tak ada seorang pun yang bisa hidup sendiri. Jiwa kepemimpinan yang tinggi adalah modal untuk bersosialisasi dan hidup nyaman dalam kebersamaan. Apa ruginya sedikit menilik lingkungan sekitar setelah terus-menerus sibuk mengejar target pribadi?

Jiwa enterpreneur seharusnya dimiliki oleh semua generasi muda untuk menahan laju ketergantungan Indonesia terhadap impor. Pemuda yang punya inovasi dan kreatifitas dapat membawa perubahan.

Ketika memutuskan untuk menjadi entrepreneur, Anda harus mempersiapkan segalanya. Bukan hanya modal, tetapi Anda juga harus memiliki mental dan karakter entrepreneur yang kuat. Berikut mental dan karakter yang harus dimiliki entrepreneur sukses :

a. Cerdas Secara Emosional 

JURNAL ABDIMAS
P-ISSN 0000-0000, E-ISSN 0000-0000

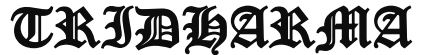
Jurnal ABDIMAS Vol. 1,No.1, Agustus 2019, Hal (102-110)

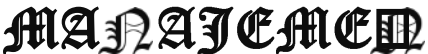

b. Niat dan Tekad Kuat

c. Disiplin Tinggi

d. Memiliki Kemauan Keras

e. Percaya Kemampuan Diri

f. Berani Mengambil Risiko

g. Pantang Menyerah

h. Jujur

i. Kreatif dan Inovatif

j. Ikhlas dan Bersyukur

Dalam pelaksanaan pencapaian kinerja yang optimal, maka dibutuhkan kompetensi karyawan yang lebih memadai dan dapat menunjang seluruh aktivitasaktivitas karyawan dalam menyelesaikan pekerjaan baik secara kualitas maupun kuantitas. Untuk menghasilkan suatu output atau tingkat pencapaian yang lebih baik, hingga keberhasilan kinerja seorang karyawan dapat diukur dari kompetensi sumber daya manusia itu sendiri dalam menuangkan hasil pemikirannya yang baik. Hal ini akan menjadi kesempurnaan seorang karyawan dalam mengaplikasikan potensinya yang sesuai dengan kompetensinya terhadap pencapaian kinerja.

$$
\text { Bila jiwa kepemimpinan }
$$
dioptimalkan, maka kualitas diri karyawan akan meningkat, karena karyawan tersebut akan menjadi pribadi yang bijaksana dan peduli dengan lingkungannya, termasuk lingkungan kerjanya. Jiwa enterpreuneur akan melatih disiplin dan kerja keras serta sikap jujur. Bila seorang karyawan memiliki karakter tersebut, tentu akan sangat bermanfaat bagi perusahaan. Karena itu, PT. Teknolabindo Penta Perkasa bekerja sama dengan dosen-dosen Universitas Pamulang menyelenggarakan acara pelatihan dengan tema Membangun Jiwa Kepemimpinan enterpreneur Muda Dalam Menghadapi Era Globalisasi.

\section{RUMUSAN MASALAH}

Dengan mempertimbangkan latar belakang yang telah disampaikan, kami berinisiatif mengadakan kegiatan pengabdian kepada masyarakat bagi karyawan muda PT. Teknolabindo Penta Perkasa yang beralamat di Jl. Bukit Gading Raya Komplek Gading Bukit Indah I/11 Jakarta 14240 mengenai pentingnya memiliki jiwa kepemimpinan dan jiwa enterpreneur bagi kaum muda milenial agar menjadi pribadi yang profesional dan humanis.

\section{TUJUAN PELAKSANAAN}

Adapun tujuan pelaksanaan kegiatan ini adalah : 

JURNAL ABDIMAS
P-ISSN 0000-0000, E-ISSN 0000-0000

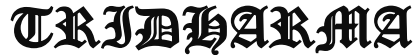
Jurnal ABDIMAS Vol. 1,No.1, Agustus 2019, Hal (102-110)

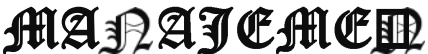
@ Prodi Manajemen Fakultas Ekonomi Universitas Pamulang
Email: abdimasjurnal.unpam@ gmail.com Telp: (021) 741-2566

1. Membantu

menumbuhkan

jiwa

kepemimpinan di kalangan kaum muda milenial.

2. Membantu menumbuhkan jiwa enterpreneur di kalangan kaum muda milenial.

\section{TINJAUAN PUSTAKA}

\section{Pengertian Manajemen}

Pengertian manajemen secara umum dapat disimpulkan dari beberapa definisi menurut para ahli. Hal ini karena ada banyak versi definisi manajemen. Misalnya saja manajemen menurut seorang ahli bernama Mary Parker Follet yang mendefinisikan manajemen sebagai seni merampungkan pekerjaan melalui orang lain. Dari definisi tersebut didapati bahwa seseorang yang bertugas sebagai manajer dapat mengarahkan dan mengatur orang lain guna mencapai tujuan organisasi.

Di sisi lain, James A.F Stoner mendefinisikan manajemen sebagai proses pengorganisasian, perencanaan, dan penggunaan SDM supaya mencapai tujuan organisasi yang sudah ditetapkan.
Secara umum, pengertian manajemen merupakan suatu seni dalam ilmu dan pengorganisasian seperti menyusun perencanaan, membangun organisasi dan pengorganisasiannya, pergerakan, serta pengendalian atau pengawasan. Bisa juga diartikan bahwa manajemen merupakan suatu ilmu pengetahuan yang sistematis agar dapat memahami mengapa dan bagaimana manusia saling bekerja sama agar dapat menghasilkan sesuatu yang bermanfaat bagi orang lain maupun golongan tertentu dan masyarakat luas.

Secara etimologis, pengertian manajemen merupakan seni untuk melaksanakan dan mengatur. Manajemen ini juga dilihat sebagai ilmu yang mengajarkan proses mendapatkan tujuan dalam organisasi, sebagai usaha bersama dengan beberapa orang dalam organisasi tersebut. Sehingga, ada orang yang merumuskan dan melaksanakan tindakan manajemen yang disebut dengan manajer.

\section{Fungsi Manajemen}

Pada dasarnya, fungsi manajemen dibagi menjadi tiga, yaitu: 


\section{JURNAL ABDIMAS \\ P-ISSN 0000-0000, E-ISSN 0000-0000

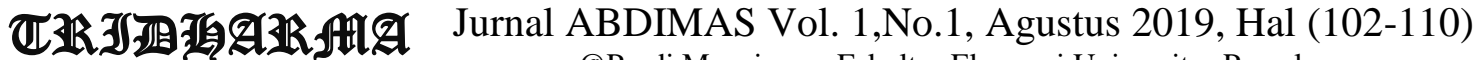 \\ AtA

a. Perencanaan (planning)

Perencanaan adalah memikirkan apa yang akan dikerjakan dengan sumber yang dimiliki. Perencanaan dilakukan untuk menentukan tujuan perusahaan secara keseluruhan dan cara terbaik untuk memenuhi tujuan itu. Manajer mengevaluasi berbagai rencana alternatif sebelum mengambil tindakan dan kemudian melihat apakah rencana yang dipilih cocok dan dapat digunakan untuk memenuhi tujuan perusahaan. Perencanaan merupakan proses terpenting dari semua fungsi manajemen karena tanpa perencanaan, fungsi-fungsi lainnya tak dapat berjalan.

b. Pengorganisasian (organizing)

Pengorganisasian dilakukan dengan tujuan membagi suatu kegiatan besar menjadi kegiatan-kegiatan yang lebih kecil. Pengorganisasian mempermudah manajer dalam melakukan pengawasan dan menentukan orang yang dibutuhkan untuk melaksanakan tugas-tugas yang telah dibagi-bagi tersebut. Pengorganisasian dapat dilakukan dengan cara menentukan tugas apa yang harus dikerjakan, siapa yang harus mengerjakannya, bagaimana tugas-tugas tersebut dikelompokkan, siapa yang bertanggung jawab atas tugas tersebut, dan pada tingkatan mana keputusan harus diambil.

c. Pengarahan (directing)

Pengarahan adalah suatu tindakan untuk mengusahakan agar semua anggota kelompok berusaha agar dapat mencapai sasaran sesuai dengan perencanaan manajerial dan usaha.

\section{Unsur-Unsur Manajemen}

Setiap perusahaan memiliki unsurunsur untuk membentuk sistem manajerial yang baik. Unsur-unsur inilah yang disebut unsur manajemen. Jika salah satu diantaranya tidak sempurna atau tidak ada, maka akan berimbas dengan berkurangnya upaya untuk mencapai

\section{a. Pengertian Manajemen Sumber Daya Manusia}

Manajemen adalah ilmu dan seni yang megatur proses pemanfaatan sumber daya manusia dan sumbersumber daya lainya secara efektif dan efesien untuk mencapai suatu tujuan tertentu. 


\section{JURNAL ABDIMAS \\ P-ISSN 0000-0000, E-ISSN 0000-0000

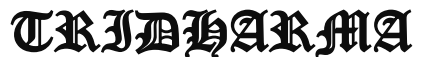 \\ Jurnal ABDIMAS Vol. 1,No.1, Agustus 2019, Hal (102-110) \\ @ Prodi Manajemen Fakultas Ekonomi Universitas Pamulang \\ AlA \\ Email: abdimasjurnal.unpam@ gmail.com Telp: (021) 741-2566}

Manajemen sumber daya manusia merupakan bagian dari ilmu manajemen yang memfokuskan perhatianya pada pengaturan peranan sumber daya manusia dalam kegiatan organisasi. Hal ini dikarnakan dalam mencapai tujuanya, organisasi memerlukan sumber daya manusia sebagai pengelola sistemnya, dan agar sistem ini berjalan, dalam pengelolaanya diperlukan beberapa aspek penting, seprti pelatihan, pengembangan, motivasi dan aspekaspek lainya. Hal ini yang menjadikan manajeman sumber daya manusia sebagai salah satu indikator penting pencapaian tujuan organisasi secara efektif dan efisien.( mila badriah, S.E., M.M, 15: 2015).

Manusia selalu berperan aktif dan dominan dalam kegiatan organisasi karena manusia menjadi perencana, pelaku, dan penentu terwujudanya tujuan organisasi. Tujuan tidak mungkin terwujud tanpa peran aktif tanpa peran karyawan meskipun alatalat yang dimiliki oleh perusahaan begitu canggih. Alat-alat canggih perusahaan tidak ada manfaatnya bagi perusahaan, jika peran aktif karyawan tidak di ikut sertakan. Mengatur karyawan merupakan hal yang sulit dan kompleks karena mereka mempunyai pikiran, perasaan, status, keinginan, dan latar belakang yang heterogen yang dibawa kedalam suatu organisasi. Karyawan tidak dapat di atur dan dikuasai sepenuhnya seperti mengatur mesin, moda, dan gedung.

Manajemen sumber daya manusia merupakan bagian dari manajemen. Oleh karna itu, teori-teori manajemen umum manjadi dasar pembahasaannya mengenai pengaturan peranaan manusia dalam menentukan tujuan yang optimal.

Pengaturan itu meliputi masalah perencanaan (human resources planning),pengorganisasian

,pengarahaan, kompenasasi, pengintregrasian,

pemeliharaan,kedisiplinan dan pemberhentian tenaga kerja untuk membantu terwujudnya tujuan perusahaan, karyawan, dan masyarakat.

Pengertian manajeman sumber daya manusia menurut malyu S.P. hasibuan ( 2005: 10 ) yang menyatakan bahwa :

"manajeman sumber daya manusia adalah ilmu dan seni yang mengatur 

JURNAL ABDIMAS
P-ISSN 0000-0000, E-ISSN 0000-0000

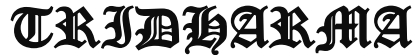
Jurnal ABDIMAS Vol. 1,No.1, Agustus 2019, Hal (102-110)
@ Prodi Manajemen Fakultas Ekonomi Universitas Pamulang
AIA
Email: abdimasjurnal.unpam@gmail.com Telp: (021) 741-2566

hubungan dan peranan tenaga kerja yang efektif dan efisien membantu terwujudnya tujuan perusahaan, karyawan, dan masyarakat".

\section{METODE PELAKSANAAN}

Metode pelaksanaan pengabdian ini dilakukan dalam beberapa kegiatan yaitu tahap survei yaitu sosialisasi dilakukan dengan menyusun berbagai hal yang akan disampaikan pada saat kegiatan pengabdian yang akan dilakukan yang meliputi: penyusunan materi yang akan diberikan, penyusunan jadwal pemberian materi, pembagian tugas tim pengabdian dan survei ke lokasi pengabdian. Tahap sosialisasi yaitu sebelum kegiatan pengabdian dilaksanakan terlebih dahulu dilakukan tahap sosialisasi yaitu melakukan silaturahmi dengan tim manajemen, menyampaikan maksud dan tujuan pengabdian ini. Pada tahap ini juga dilakukan jalinan kerjasama dan menentukan jadwal kegiatan pengabdian. Tim pelaksana kegiatan pengabdian pada masyarakat adalah dosen Fakultas Ekonomi jurusan manajemen sebanyak 5 orang. Tim pengabdian memberikan materi tentang pentingnya membangun jiwa kepemimpinan dan jiwa enterpreneur pada kaum muda milenial.

\section{HASIL DAN PEMBAHASAN}

\section{Pengabdian Kepada Masyarakat} (PKM) Universitas Pamulang yang dilakukan oleh dosen-dosen program studi Manajemen telah berjalan dengan lancar dan mendapat sambutan hangat dari karyawan PT. Teknolabindo Penta Perkasa

Harapan kami dengan pengabdian ini dapat membuka wawasan karyawa tentang pentingnya jiwa kepemimpinan dan jiwa enterpreneur agar menjadi pribadi yang humanis dan profesional sehingga bisa berperan optimal baik di tempat kerja maupun di lingkungan tempat tinggalnya.

\section{KESIMPULAN DAN SARAN}

Kesimpulan

Kesimpulan dari kegiatan pengabdian masyarakat ini adalah kaum milenial kurang memiliki jiwa kepemimpinan yang baik sehingga cenderung bersikap individualis dan apatis terhadap orang lain dan lingkungan sekitar. Kaum milenial juga belum mengembangkan jiwa enterpreneur sehingga karakter-karakter 

JURNAL ABDIMAS
P-ISSN 0000-0000, E-ISSN 0000-0000

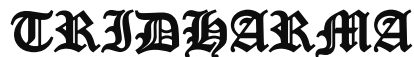
Jurnal ABDIMAS Vol. 1,No.1, Agustus 2019, Hal (102-110)

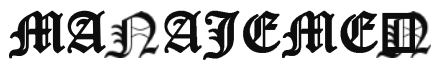
@ Prodi Manajemen Fakultas Ekonomi Universitas Pamulang
Email: abdimasjurnal.unpam@gmail.com Telp: (021) 741-2566

baik yang menyertai jiwa enterpreneur seperti disiplin, jujur, pantang menyerah dan kreatif belum terimplementasi dengan baik dalam diri mereka.

Saran

Dengan adanya pengabdian ini, generasi muda diharapkan dapat menumbuhkan jiwa kepemimpinan dalam diri mereka dan juga mengembangkan jiwa enterpreneur agar menjadi pribadi yang humanis dan profesional sehingga bisa berperan optimal baik di tempat kerja maupun di lingkungan tempat tinggalnya.

\section{DAFTAR PUSTAKA}

Kartini Kartono, 2008, Pemimpin dan kepemimpinan. Jakarta: Raja Grafindo Persada

Pasaribu, V. L. D., Susanti, F., \& Hartuti, E. T. K. (2019). MEMOTIVASI SISWA DAN SISWI SMK LETRIS INDONESIA DI DALAM MENENTUKAN PILIHAN UNTUK MELANJUTKAN PENDIDIKAN ATAU BEKERJA SETELAH LULUS SEKOLAH. Jurnal Pengabdian Dharma Laksana, 1(2), 161172.

http://kampus-pengusaha.com/tag/materientrepreneur-university/ 